\title{
PRESENTACIÓN \\ La Mixteca: estudios recientes. Arqueología, etnohistoria e iconografía
}

\author{
Manuel A. Hermann Lejarazu
}

$\mathrm{H}$

oy en día es indudable que la región mixteca ha sido identificada como una de las áreas culturales más antiguas de Mesoamérica. Sus vestigios arqueológicos y la antigüedad de sus datos atestiguan la profundidad histórica de esta extensa área situada entre los actuales estados de Oaxaca, Puebla y Guerrero. Pero para llegar al presente estado de conocimientos sobre la zona han transcurrido décadas de investigación llevadas a cabo por numerosos estudiosos de los más diversos orígenes étnicos. Basta con mencionar los trabajos pioneros de Alfonso Caso e Ignacio Bernal, las trascendentales aportaciones arqueológicas y etnohistóricas de John Paddock, Ronald Spores y Michael Lind, hasta los valiosos avances de Maarten Jansen, Mary Elizabeth Smith y Nancy Troike para el estudio de los códices. Toda esta información, en su conjunto, ha conformado un nuevo panorama sobre la historia y la cultura de la Mixteca, temática que deseamos abordar con la edición de este número de la revista Desacatos.

Mi intención principal es reunir a un grupo de investigadores que han realizado notables contribuciones a la historia y arqueología de la Mixteca en los últimos años.
Han transcurrido 25 años desde que apareció en Estados Unidos el libro The Cloud People: Divergent Evolution of the Zapotec and Mixtec Civilizations, coordinado por Joyce Marcus y Kent V. Flannery; y 24 años de que se publicó por primera vez el libro The Mixtecs in Ancient and Colonial Times, escrito por Ronald Spores. Ambas publicaciones son una referencia obligada para abordar cualquier análisis o estudio sobre la Mixteca prehispánica y colonial. Hoy en día no contamos con una publicación reciente que ofrezca de manera global las nuevas investigaciones sobre esta área. De ahí, entonces, los "saberes y las razones" para actualizar la información sobre la Mixteca, así como proporcionar nuevos textos para su discusión y análisis por parte de la comunidad académica y por todos aquellos especialistas en el tema.

\section{ARTí́culos}

Si bien el eje temático que guía la sección "Saberes y Razones" es sobre los estudios recientes sobre la Mixteca en los campos de la arqueología y la etnohistoria, quiero

The Mixteca: Recent Studies. Archaeology, Ethnohistory and Iconography

MANuel A. Hermann LejaraZU: Centro de Investigaciones y Estudios Superiores en Antropología Social-Distrito Federal, México. hermann@ciesas.edu.mx 


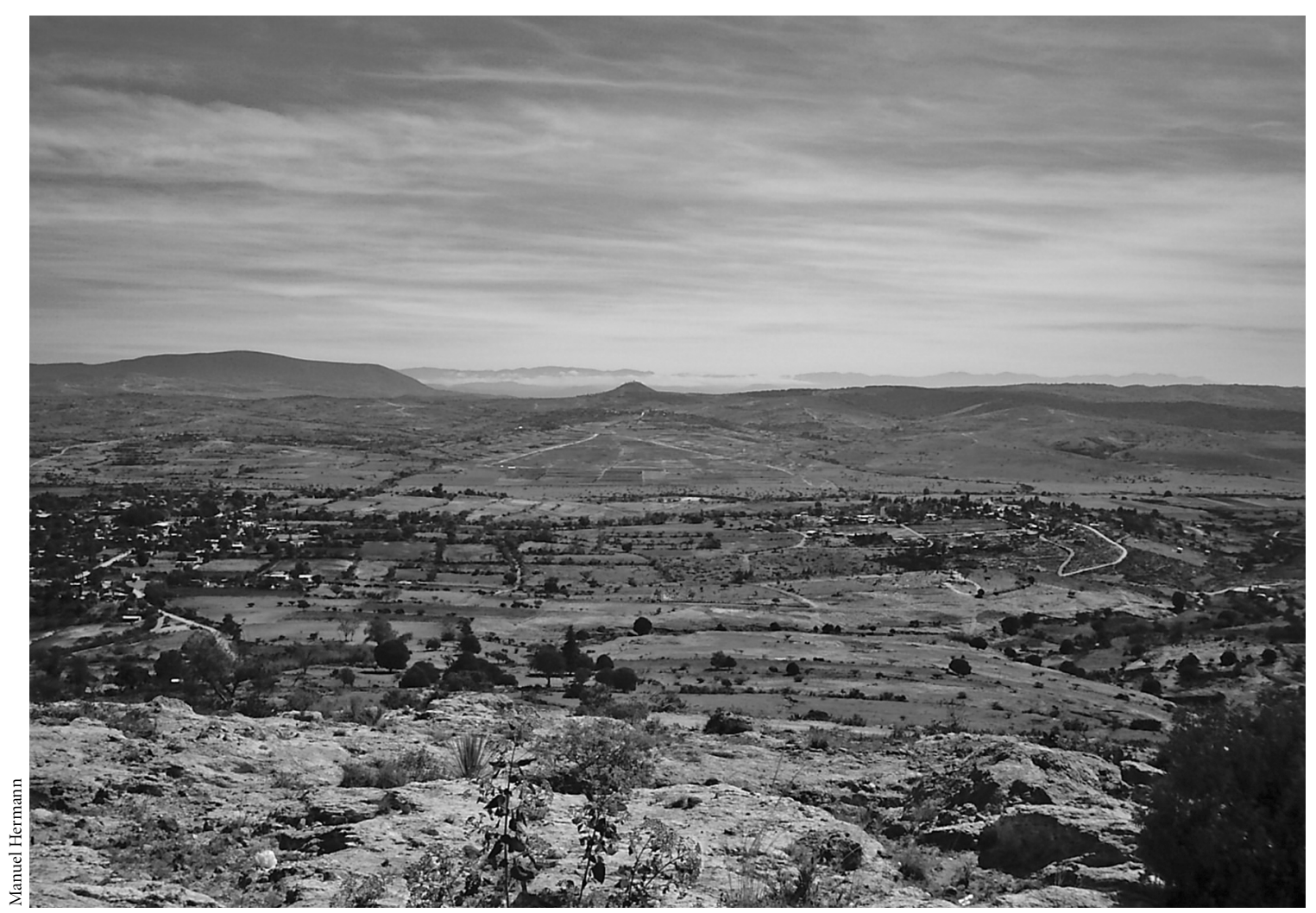

Valle de Nochixtlán.

mencionar que el aspecto iconográfico en particular ha sido abordado por los autores a lo largo de sus distintas contribuciones.

A manera de introducción ofrecemos el artículo de Michael Lind, quien nos muestra un extenso panorama sobre la arqueología, la historia y la antropología de la Mixteca antes de la llegada de los españoles. Con un gran dominio bibliográfico, el autor muestra los aspectos más sobresalientes y actualizados sobre la sociedad, la economía, las costumbres, la arquitectura, los códices y la religión. De manera particular, es notable su descripción sobre los descubrimientos más recientes en el antiguo asentamiento del pueblo de Teposcolula - hoy conocido como Pueblo Viejo-, lugar en el que se localiza el palacio o aniñe cuya estructura residencial fue el hogar de los gobernantes mixtecos junto con sus familias. Lind nos proporciona, además, información que ha sido producto de sus propias excavaciones en áreas habitacionales de diversos sitios arqueológicos ubicados en el valle de Nochixtlán, lo que enriquece de manera importante su extraordinario artículo. Finalmente, el autor se adentra en el modelo teórico de cultura ciudad-estado, término propuesto por Mogens Herman Hansen para definir a múltiples sociedades que tuvieron desarrollos culturales del tipo "ciudad-estado".

Laura Rodríguez, partiendo de un análisis muy detallado de las glosas escritas en mixteco en códices y lienzos de la Mixteca Baja, reconstruye los nombres del calendario ritual de 260 días. Sin embargo, la autora no solamente rescata el lenguaje especial que empleaban los mixtecos para designar a los días, sino que también fija su atención en las convenciones pictográficas o logográficas que se utilizaban para representarlos. Como parte novedosa de su estudio, la autora muestra por primera vez una lectu- 


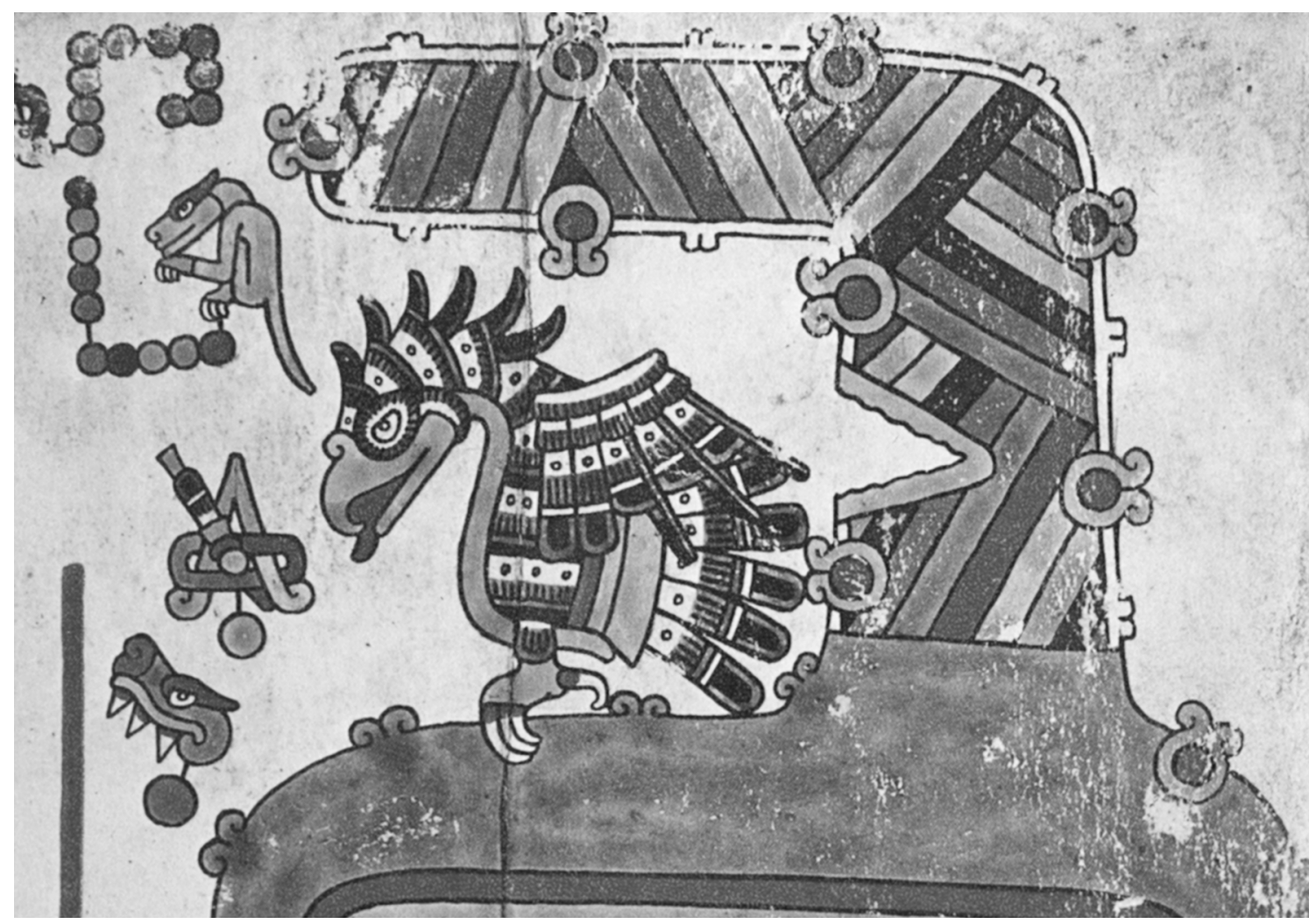

Códice Viena, anverso 3.

ra y traducción de las glosas en mixteco de los nombres calendáricos registrados en el Mapa de San Vicente el Palmar, logrando así una visión en conjunto del calendario ritual mixteco.

En un tercer artículo, quien escribe esta presentación aborda el tema sobre religiosidad y bultos sagrados en la Mixteca prehispánica. El culto al bulto sagrado es una de las actividades rituales que mayor presencia tiene en diversas partes de Mesoamérica. Existen numerosas descripciones y representaciones de bultos sagrados en fuentes coloniales y en documentos pictográficos prehispánicos, siendo la región de la Mixteca la que mayor cantidad de ejemplos presenta. Este aspecto de la religiosidad mixteca manifestada a través de los bultos se puede encontrar en rituales de fundación, ceremonias de entronización de los gobernantes, así como en las fiestas periódicas que involucraban a toda la comunidad, pero, además, en cultos particulares o privados que realizaba el dueño de algún bulto. Al parecer, el culto a los fardos sagrados estaba tan extendido en la Mixteca que quizá constituyó la principal manifestación religiosa de esta región en la época prehispánica, cambiando así nuestro paradigma sobre las formas de culto que tradicionalmente se han considerado para Mesoamérica.

Continuando con la temática etnohistórica, Sebastián van Doesburg realiza un estudio detallado sobre el significado del Lienzo de San Vicente el Palmar empleando una metodología contextual que incluye no sólo el análisis iconográfico del manuscrito, sino también un examen de todos aquellos documentos provenientes de archivos que ayudan a reconstruir el contexto histórico y social que produjo la realización del lienzo. Desde hace varios años el autor ha recurrido a esta práctica metodológica con muy buenos resultados. Ejemplo de ello son sus publicaciones 


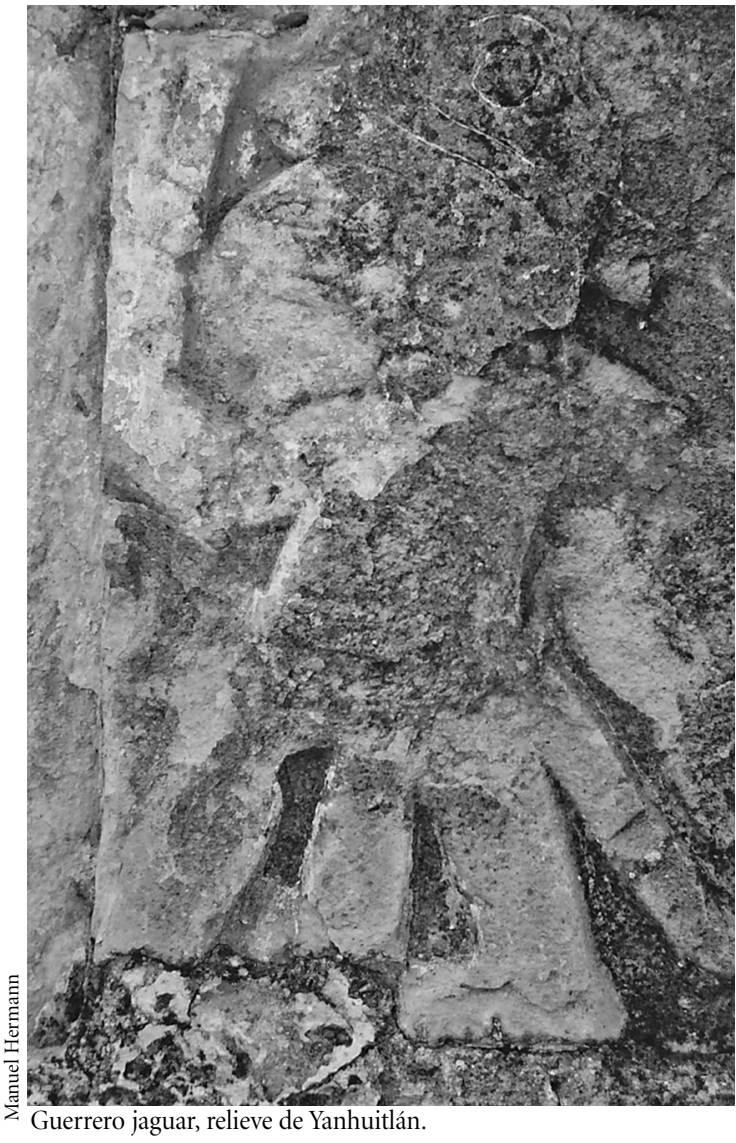

sobre el Códice Porfirio Díaz y los lienzos de Coixtlahuaca. Uno de los puntos clave para la lectura del lienzo es el trabajo que realiza van Doesburg en las comunidades mismas registradas en el documento. Su visita a los pueblos productores de sal de la Mixteca Baja constituyó el elemento fundamental para su reveladora interpretación: la identificación de las fincas salineras representadas en el lienzo y, sobre todo, su notable descubrimiento de los señoríos implicados en el asunto central que trata el manuscrito.

Finalmente, Michel R. Oudijk contribuye con un profundo y esclarecedor análisis de las tradiciones y métodos de investigación actualmente en boga para el estudio de los códices y documentos mesoamericanos. Resultado de una profunda reflexión, el autor analiza de manera crítica las bases teóricas y metodológicas de las diversas "escuelas" o "tradiciones" que existen hoy en día y ofrece ejemplos concretos de lectura de varios elementos pictóricos aplicando uno u otro método de análisis. Además, Oudijk hace hincapié en los avances, logros, implicaciones y limitaciones de cada una de las escuelas por él reseñadas, resultando un revelador artículo acerca del estado de la cuestión o de dónde podríamos situarnos antes de comenzar el estudio de cualquier documento pictórico.

Cierra la sección un importante comentario a cargo de Arthur Joyce sobre los artículos presentados en este número. Joyce realiza un examen crítico a las metodologías empleadas para el estudio de la escritura pictográfica mixteca y previene sobre los riesgos que implica la aplicación de la analogía para la interpretación de los documentos históricos. El propio autor señala que el uso de fuentes primarias debe hacerse de manera crítica, sobre todo si sus datos son manejados para realizar alguna analogía con el objeto de estudio en cuestión.

No quiero pasar por alto otras dos secciones estrechamente vinculadas con la temática de este número. Una es la sección de "Testimonios", que aborda de manera breve la importancia de los archivos parroquiales para la historia social, económica y demográfica de la Mixteca, particularmente la que se sitúa a lo largo del siglo XVIII. La segunda sección, conocida como "Legados", recoge una magnífica semblanza escrita por Marcus Winter sobre la extensa y reconocida trayectoria académica de Ronald Spores. Han transcurrido cuarenta años de la publicación de la obra The Mixtec Kings and their People (1967) y es necesario mencionar que este libro constituye un verdadero "parteaguas" en la historia y la arqueología de la Mixteca. Ron contribuyó con nuevos paradigmas para la investigación al incluir por primera vez, de manera sistemática, el análisis de los documentos coloniales para el estudio de la Mixteca. Con su profundo conocimiento tanto de la arqueología como de los archivos históricos, Ron condujo una nueva vertiente de análisis que ha servido de puente para las subsecuentes generaciones dedicadas a los estudios mixtecos. Hoy en día, muchos investigadores dedicados a la Mixteca o a Oaxaca en general reconocemos la importancia del estudio de los documentos coloniales y, en gran medida, debemos a Ron Spores los primeros resultados vertidos en su ya clásico texto. 